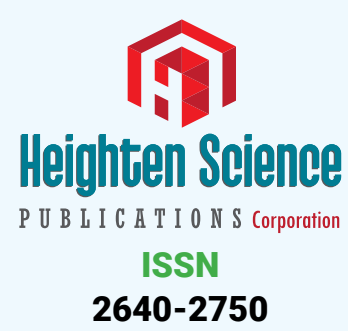

*Address for Correspondence: Eva Barreiro Alonso, Gastroenterology, University Hospital of Cabueñes, Spain

Email: evabarreiroalonso@yahoo.es

Submitted: 11 January 2018

Approved: 18 January 2018

Published: 19 January 2018

Copyright: @ 2018 Barreiro Alonso E. This is an open access article distributed under the Creative Commons Attribution License, which permits unrestricted use, distribution, and reproduction in any medium, provided the original work is properly cited

Keywords: Pyogenic; Liver abscess; Epidemiology

Check for updates
Research Article

\section{Analysis of Pyogenic Liver Abscesses}

\author{
Eva Barreiro Alonso* \\ Gastroenterology, University Hospital of Cabueñes, Spain
}

\section{Abstract}

Background: Pyogenic liver abscesses (PLA) are frequent in immunosuppressed patients. We review the characteristics of patients with PLA at a tertiary academic Spanish hospital in Asturias.

Methods: A retrospective observational study for 10 years, between 2006-2015. Epidemiological, clinical, analytical characteristics, treatment and hospital stay of the patients with PLA were analyzed.

Results: 99 patients, 62 (62.6\%) men, with age $\geq 65$ years (72.7\%). The most frequent etiology was: Biliary $(40 \%)$, postsurgical $(15 \%)$ and intestinal origin $(11 \%)$. The most frequent clinical signs were fever, showing significant differences, abdominal pain $(p=0.001)$ and nausea $(p=0.02)$ between biliary PLA and the rest of the PLA. Microbiological results were confirmed in $63 \%$ (62 cases). All were treated with antibiotic therapy, along with percutaneous drainage ( $44.4 \%$ ( 44 cases)); and surgical drainage $(12.1 \%$ ( 12 cases)). The overall mean stay was 23.1 days without significant differences between those treated with percutaneous drainage or surgical drainage.

Conclusions: PLA predominate in patients $\geq 65$ years. Biliary PLA are the most frequent, diagnosed at an older age than the intestinal PLA $(p=0.005)$.

- The treatment is based on systemic antibiotherapy and percutaneous drainage, especially in PLA only $>5 \mathrm{~cm}(\mathrm{p}=0.019)$

- There are no significant differences in average stay of patients treated with percutaneous drainage or surgical drainage.

\section{Introduction}

Pyogenic liver abscess (PLA) is defined as a collection of pus in theliver. The incidence of PLA has increased in recent decades for several reasons: immunosuppressive treatments, immunosuppressed and old patients and greater diagnostic efficacy through imaging techniques [1-3]. Most of the PLA are solitary and situated in the right lobe of the liver but the exact reason is not known [4].

The pathogens causing PLA are geographically diverse. Knowing the etiology of PLA with cultures, when possible, plays an important role in the successful therapy of PLA patients [5].

The treatment is based on antibiotherapy and drainage. Surgery remains first-line treatment of patients who present with abscess rupture, peritonitis, or a concomitant surgical condition but is otherwise reserved for failure of percutaneous drainage [6]. The percutaneous drainage could be an effective, and perhaps superior, alternative for treating PLA. The effectiveness of antibiotics alone is still disputed, with a high casefatality rate in some studies [7].

\section{Material and Methods}

A retrospective descriptive study was done at University Hospital of Cabueñes for 10 years, between 2006-2015. Epidemiological, clinical, analytical characteristics, treatment and hospital stay of the patients with PLA were analyzed. Amoebic liver abscesses were excluded. Cases were divided into the three most frequent causes of 
PLA for comparison of characterisitics. The study protocol adhered to the principles of the Declaration of Helsinki. The statistical calculations were performed by means of STATA.

\section{Results}

99 patients, $62(62.6 \%)$ men, with age $\geq 65$ years $(72.7 \%)$. The most frequent etiology was: Biliary (40\%), postsurgical (15\%) and intestinal origin (11\%). They are grouped into the three most frequent etiologies (Figure 1). The baseline and clinical characteristics are shown in table 1, and the distribution and location of PLA are shown in table 2.

There are significant differences in the age of presentation between biliary ( 74 years) and intestinal PLA (57 years) ( $\mathrm{p}=0.005)$.

The most frequent clinical signs were fever, abdominal pain $(\mathrm{p}=0.001)$ and nausea $(\mathrm{p}=0.02)$ between biliary PLA and the rest.

Analytically, we highlighted: ESR $\geq 30$ and / or CRP $\geq 30$ (83.8\%), cholestasis (71.7\%) and leukocytosis ( $\geq 12000)(59.6 \%)$.

Microbiological results were confirmed in 63\% (62 cases), with only positive blood cultures: $30.6 \%$ (19 cases), with only positive abscess cultures: $51.6 \%$ (32 cases) and both positive: $17.7 \%$ (11 cases) (Figure 2).

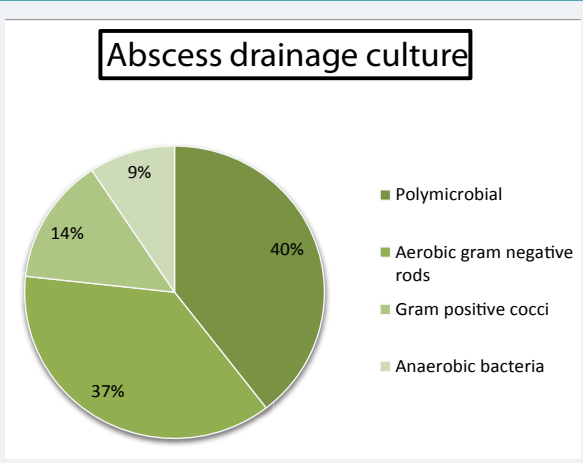

Figure 1: Microbiological results of abscess drainage culture.

Table 1: Main epidemiological and clinical characteristics of patients with one of three most frequent causes of PLA.

\begin{tabular}{|c|c|c|c|c|}
\hline & Biliary & $\begin{array}{c}\text { Postsurgical } \\
\text { complications }\end{array}$ & Intestinal origin & p value \\
\hline & Mean (SD)/ \% & Mean (SD)/ \% & Mean (SD)/\% & \\
\hline Age (years) & $73.8(12,2)$ & $70.5(14.9)$ & $57.4(19)$ & 0.005 \\
\hline Sex (Male) & 58.97 & 23.08 & 17.95 & 0.962 \\
\hline Diabetes mellitus & 20.51 & 20 & 9.09 & 0.679 \\
\hline Fever & 76.92 & 73.33 & 63.64 & 0.675 \\
\hline Abdominal pain & 92.31 & 46.67 & 72.73 & 0.001 \\
\hline Nausea & 48.72 & 20 & 9.09 & 0.019 \\
\hline Constitutional syndrome & 23.08 & 26.67 & 27.27 & 0.939 \\
\hline
\end{tabular}

Constitutional síndrome: Decreased appetite, fatigue and weight loss (unintentional).

Table 2: Type and location of PLA.

\begin{tabular}{|c|c|c|c|c|c|}
\hline & & Biliary & $\begin{array}{l}\text { Postsurgical } \\
\text { complications }\end{array}$ & $\begin{array}{c}\text { Intestinal } \\
\text { origin }\end{array}$ & $p$ value \\
\hline & & n (\%) & n (\%) & $n(\%)$ & \\
\hline \multirow{3}{*}{$\begin{array}{l}\text { Type: Size } \\
\text { category }\end{array}$} & Solitary $>5 \mathrm{~cm}$ & $12(30.77 \%)$ & $10(66.67 \%)$ & $5(45.45 \%)$ & \multirow{3}{*}{0.231} \\
\hline & Solitary $<5 \mathrm{~cm}$ & $8(20.51 \%)$ & $2(13.33 \%)$ & $2(18.18 \%)$ & \\
\hline & Multiple & $19(48.71 \%)$ & $3(20.0 \%)$ & $4(36.36 \%)$ & \\
\hline \multirow{3}{*}{$\begin{array}{l}\text { Location: liver } \\
\text { lobe affected }\end{array}$} & Right lobe & $14(35.90 \%)$ & $11(73.33 \%)$ & $7(63.64 \%)$ & \multirow{3}{*}{0.07} \\
\hline & Left lobe & $19(48.72 \%)$ & 2 (13.33) & $2(18.18 \%)$ & \\
\hline & Both lobes & $6(15.38 \%)$ & $2(13.33)$ & $2(18.18 \%)$ & \\
\hline
\end{tabular}



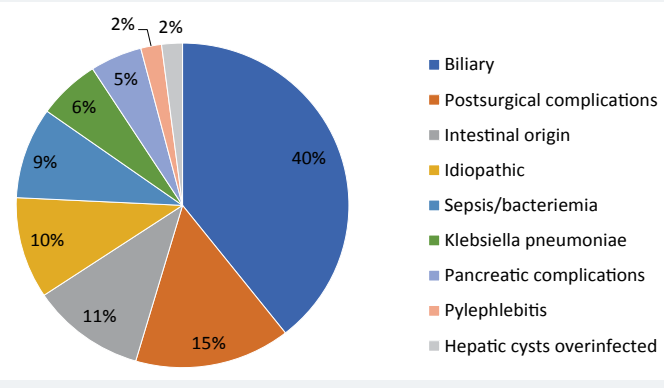

Figure 2: Aetiology of PLA.

All were treated with intravenous broadspectrum antibiotics such as piperacillin/ tazobactam, carbapenems, quinolones or amoxicillin/clavulanate, among others, according to antibiogram, along with percutaneous drainage (44.4\% (44 cases) $(61.7 \%$ in PLA solitary> $5 \mathrm{~cm}(\mathrm{p}=0.019)$, with predominance of right lobe affected $(57.4 \%)$ $(\mathrm{p}=0.34))$; and surgical drainage $(12.1 \%$ (12 cases) (50\% (6 cases) in PLA solitary> $5 \mathrm{~cm}(\mathrm{p}=0.13)$ and $75 \%$ localized in left lobe $(\mathrm{p}=0.004))$.

The overall mean stay was 23.1 days without significant differences between those treated with percutaneous drainage or surgical drainage.

\section{Discussion}

The incidence of PLA has increased in last decades. Although, PLA is a rarely encountered finding in the western population. Its detection has changed since the beginning of the last century. Nowadays, the age of presentation has increased, with hepatobiliary and cryptogenic causes being more frequent. Almost 100 patients suffered PLA in the last 10 years in our environment. About 75\% patients were $\geq 65$ years. Higher figure in comparison with other Spanish studies probably because Asturias is the oldest region of Spain [1,2]. The most frequent etiology was: Biliary (40\%), with abscesses multiples in both lobes of the liver. On the other hand, PLA by postsurgical complications and intestinal origin are solitary and situated in the right lobe of the liver. The exact reason is not known [4].

The pathogens causing PLA are geographically diverse [5]. In China, the major pathogen causing PLA is Klebsiella pneumoniae [5]. In Asturias, the majority of PLA were caused by polymicrobial germs or aerobic gram-negative germs. Microbiological results were confirmed in $63 \%$ cases. The causes of liver abscesses due to intestinal origins were: intestinal fistulas, intestinal perforation by foreign body, infectious diarrhea, or diverticulums. Coprocultures were negative in these patients.

The treatment is based on antibiotherapy according to antibiogram and drainage or surgery [6]. All were treated with antibiotic therapy, along with percutaneous drainage (44.4\% (44 cases)); and surgical drainage (12.1\% (12 cases)). There are no significant differences in average stay of patients treated with percutaneous drainage or surgical drainage, or in the complications of such techniques. The percutaneous drainage could be an effective, and perhaps superior, alternative for treating PLA [7].

\section{Conclusions}

-PLA predominate in patients $\geq 65$ years. Biliary PLA are the most frequent, diagnosed at an older age than the intestinal PLA ( $p=0.005)$.

-The characteristic clinical feature in biliary PLA was pain and nausea with significant differences with respect to the others PLA. 
-Treatment is based on systemic antibiotherapy and percutaneous drainage, especially in PLA solitary $>5 \mathrm{~cm}(\mathrm{p}=0.019)$. Eventually, surgical treatment is performed in $12 \%$ of cases, especially in those located in left lobe $(p=0.004)$.

-There are no significant differences in average stay of patients treated with percutaneous drainage or surgical drainage.

\section{References}

1. Ruiz-Hernández JJ, León-Mazorra M, Conde-Martel A, Marchena-Gómez J, Hemmersbach-Miller M, et al. Pyogenic liver abscesses: Mortality-related factors. Eur J Gastroenterol Hepatol. 2007; 19: 853858. Ref.: https://goo.gl/aQ8gse

2. Peris J, Bellot $P$, Roig $P$, Reus $S$, Carrascosa $S$, et al. Clinical and epidemiological characteristics of pyogenic liver abscess in people 65 years or older versus people under 65 : A retrospective study. BMC Geriatr. 2017; 17: 161. Ref.: https://goo.gl/nhVXC3

3. Cosme A, Ojeda E, Zamarreño I, Bujanda L, Garmendia G, et al. Pyogenic versus amoebic liver abscesses. A comparative clinical study in a series of 58 patients. Rev Esp Enferm Dig. 2010; 102: 90-99. Ref.: https://goo.gl/4Z7sXX

4. Târcoveanu E, Vlad N, Moldovanu R, Georgescu S, Bradea C, Lupaşu C, et al. Pyogenic liver abscesses. Chirurgia (Bucur). 2008; 103: 417-427. Ref.: https://goo.gl/sqEuMX

5. Luo $\mathrm{M}$, Yang X-, Tan B, Zhou X-, Xia H-, et al. Distribution of common pathogens in patients with pyogenic liver abscess in China: a meta-analysis. Eur J Clin Microbiol Infect Dis 2016; 35: 1557-1565. Ref.: https://goo.gl/uf1xKH

6. Haider SJ, Tarulli M, McNulty NJ, Hoffer EK. Liver abscesses: Factors that influence outcome of percutaneous drainage. Am J Roentgenol. 2017; 209: 205-213. Ref.: https://goo.gl/DBec4X

7. Chen SC, Tsai SJ, Lee YT, Yen $\mathrm{CH}$, Huang CC, et al. Predictors of mortality in patients with pyogenic liver abscess. Neth J Med 2008; 66:196-203. Ref.: https://goo.gl/Gf88vi 